\title{
MORPHOLOGY OF CAUDATE AND QUADRATE LOBES OF LIVER
}

\author{
Namrata Reddy', S. S. Joshi', P. S. Mittal ${ }^{3}$, S. D. Joshi ${ }^{4}$ \\ ${ }^{1}$ Assistant Professor, Department of Anatomy, Sri Aurobindo Medical College \& Postgraduate Institute, Indore. \\ ${ }^{2}$ Director and Professor, Department of Anatomy, Sri Aurobindo Medical College \& Postgraduate Institute, Indore. \\ ${ }^{3}$ Associate Professor, Department of Anatomy, KDMC \& RC, Mathura. \\ ${ }^{4}$ Director and Professor, Department of Anatomy, Sri Aurobindo Medical College \& Postgraduate Institute, Indore.
}

\section{ABSTRACT}

\section{BACKGROUND}

Anatomy of caudate lobe is complex and although it is readily visualised on abdominal imaging like CT or sonography, it shows wide range of variations in size and shapes. The quadrate lobe also shows considerable variations in size, shape and the presence of pons-hepatis and they may mimic some clinical conditions posing difficulties in interpretation and diagnosis.

Aims- Anatomy of Caudate lobe is complex and may cause difficulties in the interpretation of cross-sectional images. The detailed anatomy of the caudate and the quadrate lobes continue to be elusive to anatomist, radiologist and the surgeons for want of a precise description of these two lobes of the liver.

\section{MATERIALS AND METHODS}

80 apparently normal livers available in the department were utilised in the present study. The length and width of caudate and quadrate lobes were measured with the help of digital Vernier calliper. The various shapes of these lobes were recorded. In the caudate lobe, the presence and prominence of papillary process, the fissures and the pattern and thickness of caudate process and in quadrate lobe the dimensions, presence of accessory fissures, projections and porta hepatis were recorded and photographed.

\section{RESULTS}

Caudate Lobe: Avg. height was $4.78 \mathrm{~cm}$; avg. width was $2.54 \mathrm{~cm}$; prominent papillary process was found in $8.75 \%$ livers; incidence of fissures on CL was 43.75\%; avg. thickness of caudate process was $2 \mathrm{~mm}$. Quadrate Lobe: Avg. height was $5.48 \mathrm{~cm}$; avg. width was $2.84 \mathrm{~cm}$; incidence of fissures was $56.25 \%$; and incidence of pons hepatis was $38.75 \%$.

\section{CONCLUSION}

The findings of the present work have been compared with that of other workers. The incidence of pons hepatis, presence of papillary process are at variance from those reported by previous workers. It is expected that the findings of the present work would be of help to the surgeons doing hepatobiliary surgeries, liver transplant, and the radiologists in proper interpretation of USG and CT.

\section{KEYWORDS}

Caudate Lobe, Quadrate Lobe, Papillary Process, Caudate Process, Pons hepatis, Accessory Fissures.

HOW TO CITE THIS ARTICLE: Reddy N, Joshi SS, Mittal PS, et al. Morphology of caudate and quadrate lobes of liver. J. Evolution Med. Dent. Sci. 2017;6(11):897-901, DOI: 10.14260/Jemds/2017/192

\section{BACKGROUND}

Liver is the largest abdominal viscera occupying a considerable portion of upper abdominal cavity. Grossly it can be divided into 4 lobes and depending on its functional anatomy, liver can be divided into 8 segments (Couinaud's classification). Caudate lobe forms the 1 st segment according to this classification, but has distinctive features from other 7 segments. It is bounded on the right by the vena caval groove, on the left by the fissure for ligamentum venosum, above by the posterosuperior border and below by porta hepatis. ${ }^{1}$ The caudate lobe is a central structure of the liver that generally is seen readily on abdominal imaging studies such as CT or sonography. Caudate lobe anatomy; however, is complex and may cause difficulties in the interpretation of cross-sectional

Financial or Other, Competing Interest: None.

Submission 27-12-2016, Peer Review 19-01-2017,

Acceptance 27-01-2017, Published 06-02-2017.

Corresponding Author:

Dr. S. D. Joshi

\#204, Sapna Apartment,

39-Kailash Park Colony,

Indore-452001.

E-mail: sdjoshi_2003@hotmail.com

DOI: $10.14260 /$ jemds $/ 2017 / 192$

\section{(c) $($ ) $९$}

images. Caudate lobe may be envisioned as a midline wedge in the sagittal plane. ${ }^{2}$ Papillary process is a part of caudate lobe of liver. When large it can simulate mass lesion in pancreatic head region or periportal lymphnode on imaging. Echogenicity of papillary process is similar to liver parenchyma and knowledge of this variant may help to avoid errors. $^{3}$ Caudate lobe has independent vessels in the form of portal venous and hepatic arterial branches, which may account for its clinical importance in metastasis, cirrhosis and hepatic resections. ${ }^{4}$ The most common abnormality of the caudate lobe is enlargement. Caudate enlargement generally occurs in the setting of primary cirrhosis of any type or is caused by venous occlusion. The Quadrate lobe is quadrilateral in outline bounded on the left by fissure for ligamentum teres, on the right by fossa for gall bladder, above and behind by the porta hepatis and caudate process and below and in front by the inferior border of liver. ${ }^{1}$

Although many workers have studied in details the surface features of liver including the accessory fissures and lobes, but the detailed anatomy of the caudate and the quadrate lobes continues to be elusive to anatomists, radiologists and the surgeons for want of a precise description of these two lobes of the liver. 


\section{MATERIALS AND METHODS}

Eighty human livers collected from cadavers (Age 50-70 years) available in the Department of Anatomy were used in the present study. The livers were apparently normal without any gross pathology. The study was aimed to observe the gross anatomy, surface features and variations of caudate \& quadrate lobes. The length and width of the caudate and quadrate lobes were measured with the help of digital Vernier calliper. The fissures on the surface of caudate and quadrate lobes were also measured and recorded. The position \& extent of pons hepatis on the fissure for ligamentum teres were noted. The width \& thickness of the caudate process and the prominence of the papillary process were also recorded. Variations, if any, were observed, recorded and photographed.

\section{RESULTS}

\section{Caudate Lobe}

In $78.75 \%$ of the livers examined the Caudate Lobes were rectangular in shape followed by $16.25 \%$ were pear shaped. Other shapes found in one or two livers were pyramidal, square and irregular (Fig. $1 \mathrm{~A}, \mathrm{~B}, \mathrm{C}$ ). The average height of caudate lobe (CL) was $4.78 \mathrm{~cm}$ (Range 2.4-7.8 cm). The avg. width of CL was $2.54 \mathrm{~cm}$ (Range $1.1-3.2 \mathrm{~cm}$ ). The presence of fissures on the CL were observed in $43.75 \%$ and its average length was found to be $2 \mathrm{~cm}$. Out of these, vertical fissures were seen in $28 \mathrm{CL}(35 \%)$ and in 2 cases $(2.5 \%)$ they were transverse. Oblique fissures were observed in 6 cases i.e. $7.5 \%$, and in $2.5 \%$ CL the fissures were curved. The fissures from the inferior margin of CL were observed under two parameters. Twelve livers (15\%) had a vertical fissure separating the caudate lobe from the caudate process and 18 livers $(22.5 \%)$ showed fissures from middle of the inferior margin of CL. In one of the livers fissure on the inferior margin separated the papillary process from rest of the caudate lobe. (Figure $2 \mathrm{~A}, \mathrm{~B}, \mathrm{C}, \mathrm{D}$ ).

The average thickness of the caudate process was $2 \mathrm{~mm}$ and it showed a great variability in thickness ranging from $0.27 \mathrm{~mm}$ to $9.15 \mathrm{~mm}$. An unusual finding was the presence of a bilaminar caudate process in one of the livers. (Figure $3 \mathrm{~A}, \mathrm{~B}, \mathrm{C}$ ).

In 37 livers (46.25\%), papillary process was prominent. Out of these, it was very prominent in 7 livers. These prominent papillary processes had a broad base measuring $2.73 \mathrm{~cm}$ (Range 0.5-3.6 cm) and their average height was 2.5 cm (Range 2.0-3.02 cm) (Figure $4 \mathrm{~A}, \mathrm{~B}, \mathrm{C}, \mathrm{D})$. In 33 livers, the papillary process was just discernible, and in the remaining 10 livers (12.5\%) it was absent.

\section{Quadrate Lobe}

In $85 \%$ of the livers examined, shape of QL was quadrangular followed by rectangular in $10 \%$. Other shapes seen were triangular, pear shaped and bell shaped (Figure 5 A, B, C, D). The average height of the quadrate lobe (QL) was $5.48 \mathrm{~cm}$ (Range $2.38-9.1 \mathrm{~cm}$ ) and the width was $2.84 \mathrm{~cm}$ (Range 1.57$6.3 \mathrm{~cm})$.

The incidence of fissures on the surface of QL was $56.25 \%$ with the average length of the fissures being $2.29 \mathrm{~cm}$. Out of these, we have found the incidence of curved and horizontal fissures on the quadrate lobe with equal occurrence i.e. $39.5 \%$ and that of oblique and $\mathrm{v}$-shaped fissures being $10.4 \%$ each. The variability of these fissures on the surface of $Q \mathrm{~L}$ can't be explained (Figure 6 A, B, C, D).
The incidence of pons hepatis $(\mathrm{PH})$ was found to be $32.5 \%$. Out of these in 15 cases $(57.69 \%) \mathrm{PH}$ was present in the upper third of the fissure for ligamentum teres (FLT). In $42.3 \%$, it covered the middle third of FLT. In none of the cases the PH was present in the lower third of FLT. The average height of pons was found to be $1.53 \mathrm{~cm}$ (Range $0.78-2.4 \mathrm{~cm}$ ) (Figure 7 A, B, C, D).

In 20 livers, a well-demarcated tongue like projection was seen on the QL (Figure 8 A, B, C, D) delineated by a curved fissure. Average distance of the lower border of these processes from the inferior border of liver was $2.05 \mathrm{~cm}$ (Range 0.7-4.5 cm). These projections were present in the vicinity of FLT rather than fossa for gall bladder, and they could be lifted from their bed as they were separated from the remainder of the QL by a deep fissure (Figure $9 \mathrm{~A}, \mathrm{~B}$ ).
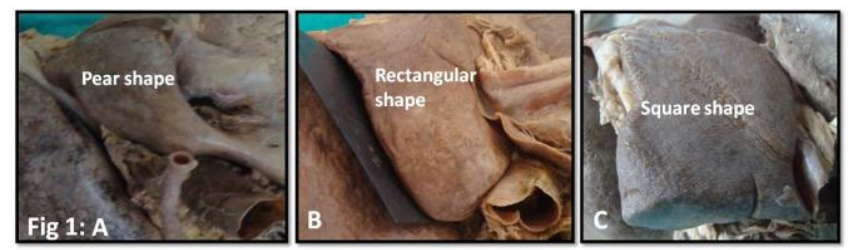

Figure 1A, B, C. Showing various shapes of CL

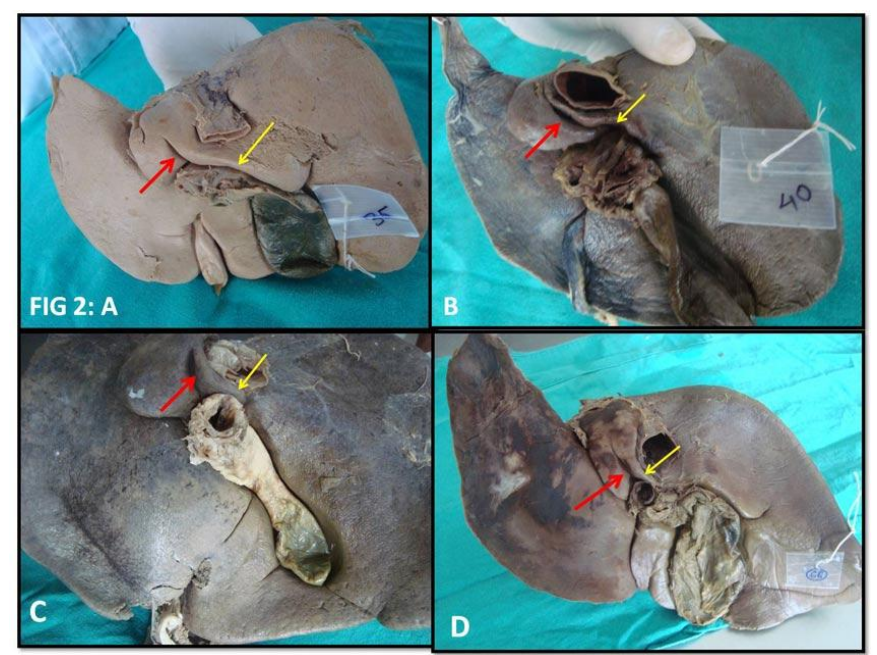

Figure $2 A, B, C$, D. Showing fissure from inferior border of $C L$ indicated by red arrow and $C P$ by white arrow



Figure 3A, B, C. Showing different types of CP 


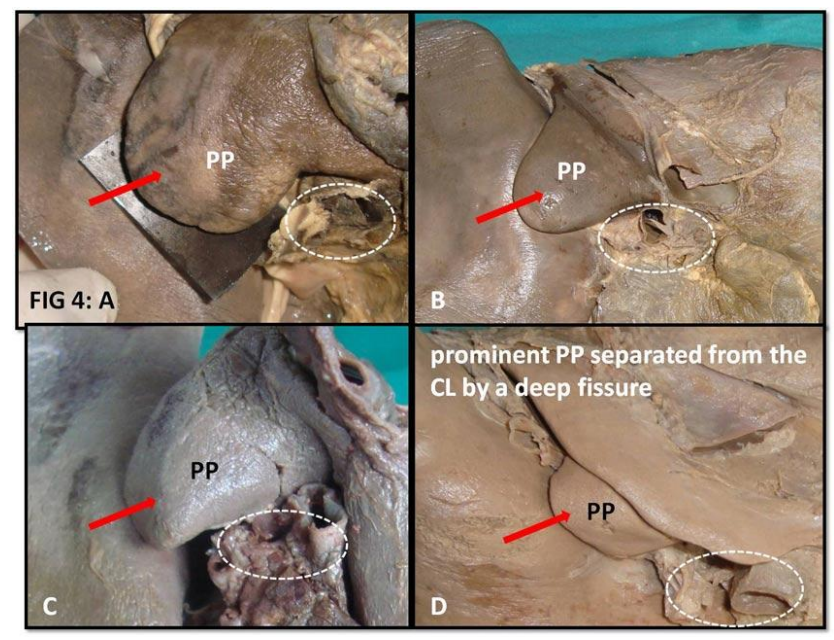

Figure 4A, B, C, D. Showing prominent PP (red arrow); porta hepatis shown by a dotted ring

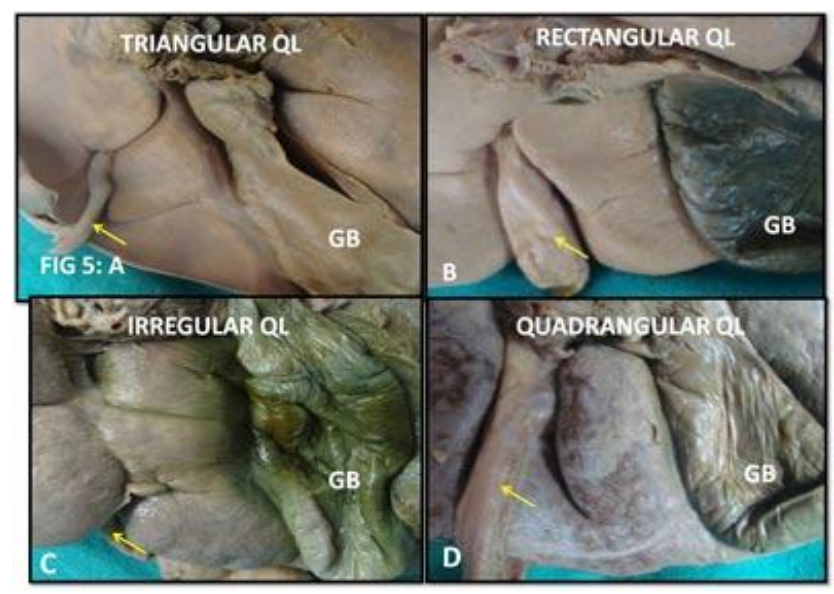

Figure $5 A, B, C$, D. Showing different shapes of QL; GB; LT by yellow arrows



Figure $6 A, B, C, D$. Showing different types of fissures on the $Q L$ by red arrows



Figure $7 A, B, C, D$. Showing the extent of pons hepatis indicated by a bracket; LT shown by red arrows

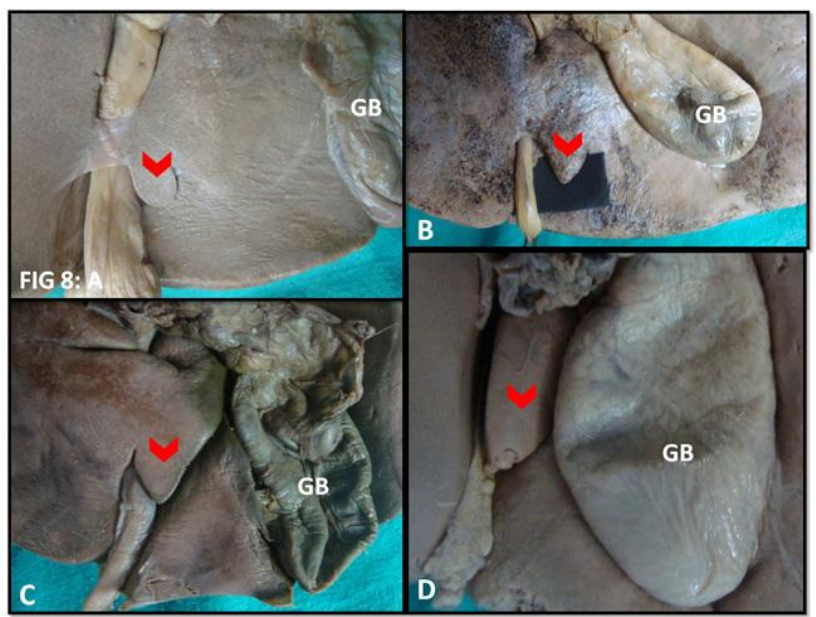

Fig $8 A, B, C$, D. Showing variable size and shape of projections of $Q L$, shown by red arrowhead; LT shown by red arrows



Fig 9A. Showing a tongue like projection separated by an oblique fissure. $B$. The projection could be easily lifted up from its bed due to this deep fissure

\section{DISCUSSION}

Development of the caudate lobe is shrouded in mystery. The caudate lobe does not belong exclusively to either the right or left hepatic lobes, but rather originates from a small portion of both hepatic lobes. Dodds et al gave a hypothesis to explain the formation of caudate lobe of liver. According to them, during second trimester, the ductus venosus rotates rightward as the liver enlarges, so that a small portion of the liver becomes inserted behind the mesentery for the ductus venosus. This part of liver gives rise to caudate lobe of liver. ${ }^{2}$ 
As stated in standard books, caudate lobe is a part of right lobe anatomically but functionally is a part of left lobe as it receives its blood supply from left branches of the hepatic artery and portal vein and delivers the bile to the left hepatic duct. The caudate lobe is comprised of two portions joined by a narrow parenchymal bridge- the caudate isthmus. One is to the left of IVC, the Spiegel's lobe or Couinaud's segment - I, the second part extends in front and to the right of IVC, the paracaval portion. The right anterior part is connected to the right lobe by the caudate process and the inferior surface of the caudate lobe presents a small rounded projection called papillary process. ${ }^{4}$

Wable et al (2014) ${ }^{5}$ have given an incidence of various shapes of caudate lobe as follows: Rectangular $48 \%$, pear shaped $25 \%$, oval $14 \%$, square $6 \%$, triangular $4 \%$ and inverted flask shaped in $2 \%$. Sahani et al $(2000)^{6}$ have found rectangular shape in $94.5 \%$ livers studied. Sarla et al (2015) ${ }^{4}$ in their study found rectangular shape in $58 \%$, pear shape in $10 \%$, irregular in $20 \%$, and triangular in $8 \%$. Joshi et al. (2009) 7 found a rectangular shape in $58 \%$ and a bicornuate shape in $20 \%$. In the present study, $78.75 \%$ caudate lobes were rectangular in shape followed by $16.25 \%$ pear shaped. Other shapes found in one or two livers were pyramidal, square and irregular. Thus, majority of CL have a rectangular shape followed by pear shape. (Figure $1 \mathrm{~A}, \mathrm{~B}, \mathrm{C}$ ).

In the present study, the average height of CL was $4.78 \mathrm{~cm}$ (Range 2.4-7.8 cm) and the average width was $2.54 \mathrm{~cm}$ (Range 1.1- $3.2 \mathrm{~cm}$ ). Wable et $\mathrm{al}^{5}$ reported a higher value than our findings i.e. height $6 \mathrm{~cm}$ and width $3-4 \mathrm{~cm}$. Sahni et al ${ }^{6}$ have also reported a greater height of $7.2 \mathrm{~cm}$ and width of 4.1 $\mathrm{cm}$. In the literature reviewed, no other workers have measured the height and width of CL. It is probable that these differences may be accounted for the nutritional status and the built of the population under study.

Wable et al ${ }^{5}$ observed a notch at the inferior border of CL in $54 \%$ of cases. Sarla et $\mathrm{al}^{4}$ found it in $31 \%$ of cases which separated the caudate lobe from the caudate process. In $30 \%$ of livers studied, they also observed vertical fissures which extended upward from the inferior border. Joshi et $\mathrm{al}^{7}$ reported a notching at the inferior border of CL and in 30\% presence of vertical fissure extending upwards from the inferior border. The sonographic appearance of papillary process separated from the caudate process of liver by a fissure was reported by Dev et al (2014). ${ }^{3}$ They further stated that 2 out of 5 patients with this anatomical variant mimicked a mass lesion. In the present study, we found the vertical fissures in $35 \%$ of the livers examined which is comparable to the observation of other workers.

Saritha et al (2015) ${ }^{8}$ have reported the incidence of pons hepatis in $4 \%$ of livers. Patil et al $(2014)^{9}$ found it in $10 \%$ of specimens examined. Joshi et al $^{7}$ found a higher incidence $(30 \%)$ of $\mathrm{PH}$; and have specified the location of pons hepatis as follows: In the majority it is present in the upper third of FLT; and in 2 cases they reported a complete pons hepatis which bridged over the complete length of FLT. In the present study, $\mathrm{PH}$ was observed in 26 cases $(32.5 \%)$ which is very close to that reported by Joshi et al. In the present study, more than half $(57.69 \%) \mathrm{PH}$ bridged the upper $1 / 3^{\text {rd }}$ of FLT, and in $42.3 \%$ it covered the middle third of FLT. In none of the livers, pons hepatis covered the lower $1 / 3^{\text {rd }}$ of FLT.

Dev et $\mathrm{al}^{3}$ have described that a tongue like process with attenuation of hepatic tissue was seen arising from caudate lobe of liver -papillary process, which extended into portocaval area and more towards left, anterior to abdominal aorta measuring approximately $4.6 \times 1.2 \mathrm{~cm}$ in size, and called it a rare anatomical variant of liver. A prominent papillary process (PP) was seen in $46.25 \%$ of livers examined in the present study, out of these $18.9 \%$ had very prominent PP. Sahni et al ${ }^{6}$ reported the presence of PP in $33 \%$ of the livers examined. Wable et al ${ }^{5}$ reported that the PP was absent in all the livers examined. The accessory CL as reported by Chhabra et al (2014), ${ }^{10}$ from the description given, seems to be a prominent PP. Papillary process when large can simulate mass lesion in pancreatic head region or periportal lymphnode on imaging; however, liver tissue characteristics and continuity of the process with the caudate lobe facilitate the differentiation between extrahepatic portocaval mass and papillary process. ${ }^{3}$

Sarla et $\mathrm{al}^{4}$ found a prominent caudate process (CP) in $9 \%$ of livers. But, in the present series, all the livers examined showed the $\mathrm{CP}$ which were easily discernible. It varied in its thickness from $0.27 \mathrm{~mm}$ to $9.15 \mathrm{~mm}$. In one liver, CP was very thick (Figure 3A), in another it was worm like (Figure 3B). It was bilaminar in one liver (Figure $3 \mathrm{C}$ ). We did not come across any description regarding the variability in the thickness and shape of caudate process in the literature reviewed.

In the present study, shape of quadrate lobe (QL) was quadrangular in $85 \%$, followed by a rectangular shape in $10 \%$. Other shapes seen in some livers were triangular, pear shaped and bell shaped (Figure $5 \mathrm{~A}, \mathrm{~B}, \mathrm{C}, \mathrm{D})$. Joshi et al ${ }^{7}$ showed $66 \%$ of livers to be rectangular and $6 \%$ as narrow. It seems that the rectangular shapes described by them probably refers to quadrangular shape of the present study.

We found that the average height of QL was $5.48 \mathrm{~cm}$ (Range 2.38-9.1 cm) and width was $2.8 \mathrm{~cm}$ (Range 1.57-6.3 $\mathrm{cm})$. No comparable data about height and width of QL was found in the literature reviewed.

Saritha et $\mathrm{el}^{8}$ found transverse fissure on the QL in $2 \%$ cases. A very high incidence $(35.48 \%)$ was reported by Jayshree et al (2013). ${ }^{11}$ Patil et $\mathrm{al}^{9}$ described the presence of transverse fissure dividing the QL into upper and lower parts without mentioning its incidence. In $20 \%$ cases, Joshi et al 7 found the fissures on the QL. In the present study, a much higher incidence of these fissures i.e. 56\% was found on the QL. The variability of these fissures on the surface of QL cannot be explained. We have found the incidence of curved and horizontal fissures on the quadrate lobe with equal occurrence i.e. $39.5 \%$ and that of oblique and v-shaped fissures being $10.4 \%$ each (Figure $6 \mathrm{~A}, \mathrm{~B}, \mathrm{C}, \mathrm{D}$ ).

Suzuki et al (1977) ${ }^{12}$ found a tongue like protrusion from the QL in one case, while performing peritoneoscopy and percutaneous transhepatic portography. Saritha et al 8 and Nayak et al (2013) ${ }^{13}$ described additional lobes in relation to the QL but have not given any details regarding its shape. We have found projections of variable sizes (Figure $8 \mathrm{~A}, \mathrm{~B}, \mathrm{C}, \mathrm{D}$ ) from the upper part of QL in $25 \%$ of livers examined. These projections were present in the vicinity of FLT rather than fossa for gall bladder. The reason for the formation of these projections from the QL cannot be explained.

Ebby et al (2012) ${ }^{14}$ showed complete absence of QL in a case reported by them. Absence of QL has also been reported by Aktan et al (2001) 15 in 3.7\% cases and have mentioned anomalous QL in $29.6 \%$ cases without any elaboration. Joshi 
et $\mathrm{al}^{7}$ have also reported the absence of QL in 2 cases. In the present series, we have not found any absence of QL.

\section{SUMMARY AND CONCLUSION}

Very few workers have studied the detailed anatomy of CL and QL of liver. The presence of fissures on these lobes demarcated by a part of liver tissue may pose difficulty in evaluating liver anatomy and pathology during USG and CT. The prominent $\mathrm{PP}$, the variable $\mathrm{CP}$, presence of $\mathrm{PH}$, and tongue like projections from the QL have been described in detail in the present work and it is expected that it would be of help to the surgeons doing hepatobiliary surgeries, liver transplant, and the radiologists in proper interpretation of USG and CT.

\section{Abbreviations \\ CL- Caudate Lobe. \\ CP- Caudate Process. \\ PP- Papillary Process. \\ QL- Quadrate Lobe. \\ GB- Gall Bladder. \\ LT- Ligamentum Teres.}

\section{REFERENCES}

[1] Dutta AK. Essentials of human anatomy. part-I: Thorax and Abdomen. The Liver. Current Books International 2014:211-3.

[2] Dodds WJ, Erickson SJ, Taylor AJ, et al. Caudate lobe of the liver: anatomy, embryology, and pathology. AJR Am J Roentgenol 1990;154(1):87-93.

[3] Dev G, Sharma R, Sharma B. Hepatic papillary processan anatomic variant of liver. JK Science Journal of Medical Education and Research 2014;16(4):184-5.

[4] Sarala HS, Jyothilakshmi TK, Shubha R. Morphological variations of caudate lobe of the liver and their clinical implications. Int J Anat Res 2015;3(2):980-3.
[5] Chavan NN, Wabale RN. Morphological study of caudate lobe of liver. Indian Journal of Basic and Applied Medical Research 2014;3(3):204-11.

[6] Sahni D, Jit I, Sodhi L. Gross anatomy of the caudate lobe of the liver. J Anat Soc India 2000;49(2)123-6.

[7] Joshi SD, Joshi SS, Athavale SA. Some interesting observations on the surface features of the liver and their clinical implications. Singapore Med J 2009;50(7):715-9.

[8] Saritha S, Ramani, Nagajyothi, et al. Cadaveric study of morphological variations in the human liver and its clinical importance. International Journal of Medical Science And Clinical Inventions 2015;2(6):1020-31.

[9] Patil S, Sethi M, Kakar S. Morphological study of human liver and its surgical importance. Int J Anat Res 2014;2(2):310-4.

[10] Chhabra N, Shrivastava T, Garg L, et al. An anatomic variant caudate lobe in a cadaver. Int J Res Med Sci 2014;2(2):759-61.

[11] Vinnakota S, Jayshree N. A new insight into the morphology of human liver: a cadaveric study. ISNR Anatomy Article ID 689564, 2013;2013:6.

[12] Suzuki K, Okuda K, Musha H, et al. False positive liver scan caused by anomalous quadrate lobe and right portal branch. Acta Hepatogastroenterol 1977;24(1):27-9.

[13] Nayak BS. A study on the anomalies of liver in the south Indian cadavers. Int J Morphol 2013; 31(2):658-61.

[14] Ebby S, Ambike MV. Anatomical variation of ligamentum teres of liver-a case report. Webmed Central Anatomy 2012;3(5):WMC003389.

[15] Aktan ZA, Savas R, Pinar Y, et al. Lobes and segment anomalies of the liver. J Anat Soc India 2001; 50(1):15-6. 